\title{
Hydropedological insights when considering catchment classification
}

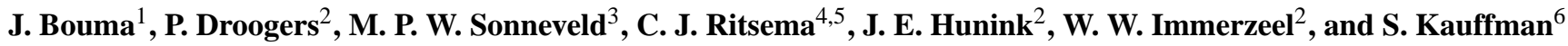 \\ ${ }^{1}$ em.Professor of soil science, Wageningen University, The Netherlands \\ ${ }^{2}$ FutureWater, Wageningen, The Netherlands \\ ${ }^{3}$ Land Dynamics Group, Wageningen University, The Netherlands \\ ${ }^{4}$ Alterra, Wageningen, The Netherlands \\ ${ }^{5}$ Land Degradation and Development Group, Wageningen University, The Netherlands \\ ${ }^{6}$ ISRIC Wageningen, The Netherlands
}

Received: 25 January 2011 - Published in Hydrol. Earth Syst. Sci. Discuss.: 28 February 2011

Revised: 9 May 2011 - Accepted: 7 May 2011 - Published: 22 June 2011

\begin{abstract}
Soil classification systems are analysed to explore the potential of developing classification systems for catchments. Soil classifications are useful to create systematic order in the overwhelming quantity of different soils in the world and to extrapolate data available for a given soil type to soils elsewhere with identical classifications. This principle also applies to catchments. However, to be useful, soil classifications have to be based on permanent characteristics as formed by the soil forming factors over often very long periods of time. When defining permanent catchment characteristics, discharge data would therefore appear to be less suitable. But permanent soil characteristics do not necessarily match with characteristics and parameters needed for functional soil characterization focusing, for example, on catchment hydrology. Hydropedology has made contributions towards the required functional characterization of soils as is illustrated for three recent hydrological catchment studies. However, much still needs to be learned about the physical behaviour of anisotropic, heterogeneous soils with varying soil structures during the year and about spatial and temporal variability. The suggestion is made therefore to first focus on improving simulation of catchment hydrology, possibly incorporating hydropedological expertise, before embarking on a catchment classification effort which involves major input of time and involves the risk of distraction. In doing so, we suggest to also define other characteristics for catchment performance than the traditionally measured discharge rates. Such characteristics may well be derived from societal issues being studied, as is illustrated for the Green Water Credits program.
\end{abstract}

\section{Introduction}

Many scientific disciplines have published classifications of their objects of study. Soil science is a good example (e.g. Soil Survey Staff, 1999; FAO, 2006). So far, there is, however, no widely accepted protocol for hydrological catchment classification and questions can be raised as to why this has not occurred and if a major effort should be made at this point in time to develop such a classification. As soils constitute the upper layer of each catchment, forming its "skin", their role in the partition, storage and transfer of water and solutes is likely to be expressed somehow in whatever catchment classification may ultimately be established. Infiltration processes into soil are crucial as is lateral flow above slowly permeable subsurface soil horizons, a variety of which is distinguished in soil classification. The recent development of hydropedology (Lin et al., 2006; Bouma, 2006) may facilitate the incorporation of soil in any catchment classification scheme as it allows transformation of relatively static soil classification data into dynamic hydrological parameters allowing the definition of soil water regimes. In summary, the objective of this paper is to: (i) broadly discuss basic characteristics of classification schemes, focusing on soil science as an example; (ii) explore the potential of hydropedology in characterizing the dynamic behaviour of soil water regimes at different scales in space and time in the context of catchment hydrology; (iii) provide some examples of using hydropedological data in modelling water movement in catchments, and (iv) discuss possible implications for the development of catchment classification schemes.

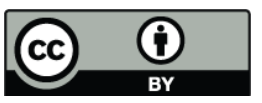

Correspondence to: J. Bouma

(johan.bouma@planet.nl)

Published by Copernicus Publications on behalf of the European Geosciences Union. 


\section{Soil classification}

Classification can be justified as a scientific activity following different lines of reasoning, to be illustrated here for soil science:

i. The scientific approach, where basic curiosity is the primary driving force and where applications are not seen as an objective. Focus is on soils as they are formed in space and time under interacting soil forming factors: parent material, climate, topography and biota, including humans. Some have regarded it as the primary purpose of soil classification to discover scientific laws (Smith, 1965). Others have even claimed that classification is the most important activity for science in general (Gerasimov, 1964);

ii. Creating the possibility to extrapolate knowledge obtained by measurements in a certain soil classification unit to another unit elsewhere for which no information is available except its identical classification. Formally, in the US system of Soil Taxonomy (Soil Survey Staff, 1999) the lowest level of the soil series serves as a major vehicle to transfer soil information and research knowledge from one soil area to another. Soil series are classes of soil bodies (polypedons) that have limits and ranges more restrictive than all higher taxa (Soil Survey Staff, 1999). Thus, classification can be effective to extrapolate knowledge involving a substantial cut in cost because without classification any new soil observation would present a new challenge requiring a complete set of new measurements;

iii. Classification schemes require definition of soil characteristics to be applied as differentiating or diagnostic criteria at different levels in the scheme. Soils vary widely in the field, even at short distances. Discussing classification schemes requires standardization of procedures, separating what are considered to be major reflections of the soil forming factors from the minor ones. Standardization also involves selection of specific indicators, to be measured with methods that are accessible and not too costly. This discussion and selection process provides a useful structure, focus and guideline for an otherwise overwhelming confrontation with the variation encountered in the field (i).

iv. Following point (iii), classification can also provide important input into planning of soil research. Research should preferably be focused on major and not minor effects of the soil forming factors and their measurement in space and time. As researchers, we want environmental policies to take account for spatial variability in the best possible way. Therefore, we should supply policy makers and planners with standardisations that are understandable and include the most relevant variability of our subject, and: v. Communication to land users and politicians is significantly enhanced when soils have a name. In the USA, the lowest level of soil classification, the soil series, has been named after localities where they occur. An Antigo silt loam, for example, occurs near the city of Antigo in Wisconsin and this inspires local ownership. Many States in the USA have State Soils and a monolith of that particular soil can often be found in the halls of the State Capitol. In other countries, such as the Netherlands, soil classifications are strongly based on local farmers knowledge and field names. This facilitates the adoption of these terms by interested citizens. An additional advantage is that soils are usually beautiful in terms of color patterns. This not only inspires artists but also contributes to effective communication. But what is being communicated? Beauty is a legitimate focal point but has a limited significance when focusing on the solution of pressing land use or water management problems. Communicating a soil name, as such, has limited appeal as well, the more so because soil names at higher levels than the soil series can become rather complicated, transmitting information only to experts (e.g. "very fine, mixed, mesic, Typic Haplaquod" following Soil Survey Staff, 1999). The real value for society is to be derived from information about expected soil behaviour that is attached to a given classification unit. However, as stated above, the soil forming factors and associated processes that have resulted in the morphology of a given soil profile do not necessarily represent actual physical, chemical and biological processes that determine soil behaviour. A functional analysis is therefore needed to "translate" properties of a given soil type into actual dynamic processes determining soil behaviour (see also e.g. Bouma, 1989; Stolte et al., 1996, 2003; Hessel, 2003; Bouma et al., 2011).

To facilitate application of classification schemes, modern classification systems such as Soil Taxonomy (Soil Survey Staff, 1999) and the World Reference Base for Soil Resources (FAO, 2006) and many other national systems not discussed here, emphasize use of visible, morphometric features when classifying soils. In other words, a trained soil scientist should be able to classify soils in the field on the basis of visual observations without immediately requiring elaborate chemical or mineralogical analyses. They are needed later, of course, to document soil properties and differentiating characteristics for classification. This is an attractive aspect of modern soil classification as it strongly increases operational efficiency.

What do we learn from soil classification in the process of developing catchment classification systems? Three observations need to be made: (i) Soils form a continuous entity in the field covering the entire surface of the solid earth except at locations where bedrock surfaces. This is in stark contrast with, for example, birds and plants that are distinct entities 


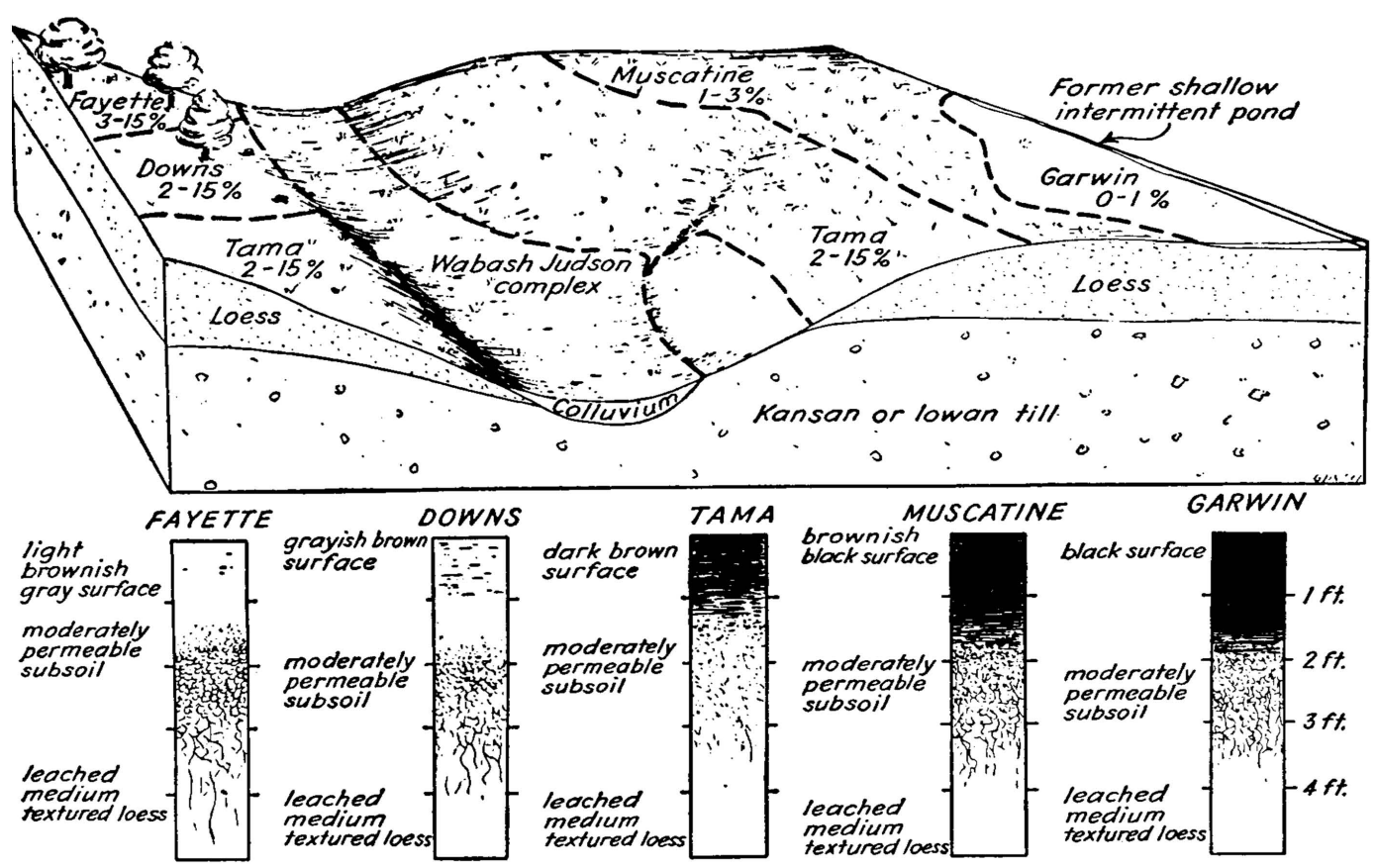

Fig. 1. Block diagram of soils in an Iowa catchment, USA, showing characteristic differences of soil types on the plateaus, the slopes and the valleys and demonstrating the importance of the soil forming factors parent material and topography.

by themselves and are therefore relatively easy subjects for classification. Soil classification is based on definition of artificial and conceptual "pedons" and "polypedons" with an arbitrary surface area of several square meters and a depth to which the pedogenetic processes extend and are in practice defined by a boring or a soil pit. In classification, a distinction is made between central concepts that reflect the ideal characteristics of the class and intergrades that belong to a class but grade into another class. More recent approaches have captured this using fuzzy techniques, also for land evaluation purposes (e.g. Sonneveld et al., 2010). Also multiple measurements of moisture retention and hydraulic conductivity have been made within large mapping units providing average curves but also standard deviations (Bouma, 1989), allowing Monte-Carlo simulations to express spatial variability. This allows, in principle, to present data-bands rather than curves.

In conclusion: pedons and polypedons cannot be observed as discrete entities. Catchment areas are usually better defined as spatial units but they are not discrete entities either. This creates specific problems for classification.

(ii) Classification is focusing on permanent soil features that have formed under influence of the soil forming factors over periods of hundreds to thousands of years. Soil classification defines "the house" and not its inhabitants and their movements in and out of the house! Acts of soil management, such as plowing, should not change a given classification as this would reduce its usefulness. This aspect often results in misunderstandings by users of soil information who are primarily interested in actual soil functionality and not in classification. Functional characterization of pedological entities has two aspects: The first aspect is that what is pedologically different is not necessarily different from a functional point of view. Bouma (1989) showed that different soil horizons in a given soil had identical hydraulic characteristics. Also, different soil series in a given parent material had comparable hydrological properties as well. The second aspect is that what is pedologically identical is not necessarily identical from a hydraulic point of view. This was the reason for Droogers and Bouma (1997), Pulleman et al. (2000) and Sonneveld et al. (2002) to introduce the concept of phenoforms, next to genoforms, the latter distinguished by soil classification and based on more or less permanent soil properties. Different phenoforms are formed for a given genoform as a function of different types of soil management: a given soil, used for example as meadow or as arable land or occurring in a nature area has significantly different physical, chemical and biological properties that strongly affect its functionality, certainly in a catchment context as it affects infiltration and subsurface movement of water over plowpans and the like. Indications are that each genoform has a characteristic range of phenoforms defining the potential range of soil properties to be realized by different forms of management. Unfortunately, phenoforms of major soil types have not as yet been systematically studied elsewhere. Stolte et al. (1996) used functional characterization of soils, measured and modelled infiltration and runoff in three small watersheds in the south of the Netherlands and showed that infiltration could be 
better described by soil structure of surface soil as affected by soil management rather than by its texture. They also showed that soil structure at any given location also changed significantly during the year. This demonstrates the complexity of characterizing infiltration processes in soils under field conditions. In conclusion: permanent soil features are needed for soil classifications but they may not adequately reflect actual hydraulic behaviour. This requires additional data related to dynamic processes. Analogous to this, the classification of catchments cannot be based on only permanent characteristics but should also not be solely based on widely available discharge data. Note that the important effects of land use are not considered in formal soil classifications whereas the authors believe that incorporating land use effects improves both the functional characterisation of soils as well as catchments.

(iii) Soil classification has most often been used to serve as a basis for the legends of soil maps that show the occurrence of different types of soil in a landscape. This can be done at different spatial scales. Conceptual three-dimensional models (Figs. 1 and 2) are used to illustrate the relationships between the occurrences of different types of soil in different parts of the landscape. Originally, soil surveyors walked through the fields, making an occasional boring while drawing boundaries between adjacent soil types on the basis of topographical or other observed differences, thereby defining "representative" soils for each map unit. The mapping units were assumed to contain at least $70 \%$ of the "representative" soil but this was not documented and the percentage was often much lower (e.g. Kuilenburg et al., 1982). Still, from a functional point of view mapping units can be more homogeneous. Currently, techniques are used to better express spatial variability by making statistically-defined multiple measurements, using remote and proximal sensing, digital mapping techniques, fuzzy set theory and geostatistics to translate point data to area data, including estimates of map purity and variability. The new research field of digital soil mapping offers new possibilities to express soil variability in space and time, not considering soil classification but with a focus on soil and landscape properties and features (e.g. Lagacherie, 2008). As we focus on the possible role of soil classification, digital soil mapping will not further be discussed. Map legends also include broad descriptions of soil water regimes in terms of: well, moderately well, poorly and very poorly drained, indicating increasing wetness. These qualitative, empirical statements are, of course, not adequate to feed modern simulation models for water regimes of catchments but they are a start and are valuable when compared with no information at all. In conclusion: soil maps suggest to the uninitiated observer occurrence of adjacent homogeneous areas of soils in a given catchment. This is not correct but techniques are available to express internal variabilities. Unfortunately, (costly) variability studies do not receive much emphasis in soil studies at this time.

\section{Hydropedology}

One of the objectives of hydropedology (Lin et al., 2006; Bouma, 2006) is to combine field expertise of soil scientists mapping soils (pedologists) with process knowledge of soil physicists and hydrologists, combining the best of the two scientific fields. Widely used pedotransfer functions have been proposed to "translate" static soil properties needed for classification into dynamic properties to be used for simulating soil water regimes in soils and catchment areas (Bouma, 1989; Pachepsky and Rawls, 2004). These functions are an early expression of hydropedology and use soil properties from soil survey, such as texture, organic matter content and bulk density and relate those data by regression to parameters for dynamic simulation, such as moisture retention and hydraulic conductivity. Indiscriminate use of pedotransfer functions can, however, yield poor results as they only reflect measurements of a limited range of soils which may not relate to the soils to be characterized. But pedological data can be much more useful beyond the context of pedotransfer functions which is increasingly recognized as the limitations of standard flow theory, in essence assuming soils to be isotropic and homogeneous, become painfully clear (Beven, 2006). Hydropedology studies have used modern soil physical methods and theory to characterize flow regimes under natural, heterogeneous soil conditions with the objective to obtain flow parameters and boundary conditions for flow systems that are more in agreement with heterogeneous conditions in the field. Detailed reports are provided elsewhere but relate to: (i) the effect of sample volume on measurement of the hydraulic conductivity in structured soils (Bouma, 1992) (i, ii) bypass flow (sometimes also called: "preferential flow"), which is the rapid vertical movement of free water through vertical macropores in an unsaturated soil matrix (Bouma, 1981; Booltink and Bouma, 2002); (iiii) internal catchment, which is accumulation of free water in deadend macropores after bypass flow (Stiphout et al., 1987) and (iv) soil hydrophobicity, leading to unexpected surface runoff and rapid transport of water through preferential flow paths (Ritsema et al., 1993, 2005). Many other studies have been made on water movement in heterogeneous soils with macropores but they were usually not related to soil morphology and soil classification which is the theme of this paper.

An example of bypass flow and internal catchment is presented in Fig. 3 (from Stiphout et al., 1987) where two showers of $10 \mathrm{~mm}$ were applied within half an hour to a clay loam soil with worm-channels acting as water conducting macropores. Water content measurements with the neutron probe were made within the hour. Simulations, using the standard homogeneous model representation predicted wetting to a depth of $5 \mathrm{~cm}$. But free water rapidly reached depths of $60 \mathrm{~cm}$ where most worm channels ended at the boundary of a sandy subsoil and at $140 \mathrm{~cm}$ where all channels ended, representing the depth where worms move in very dry periods. When internal catchment occurs on slopes, it can lead 


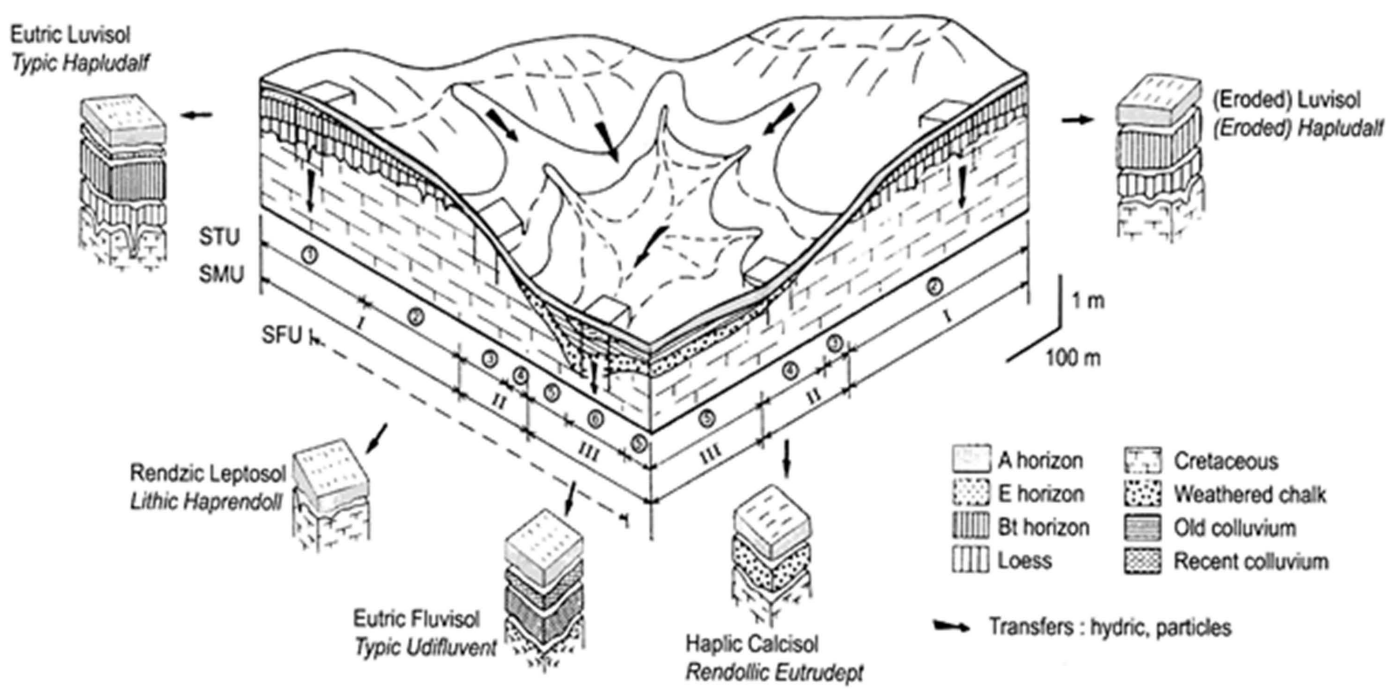

Fig. 2. Block diagram from the basin of Paris, illustrating the occurrence of different types of soil at different positions in the landscape. This diagram includes limestone bedrock, deep soils on the plateaus, thin ones on the slope and deep ones in the valleys. Streamlines of surface flow of water are determined by infiltration rates at the surface and by topography.

to unexpected landslides as free water accumulates at a given depth. Simulation models can easily be modified to take the mentioned processes into account by using morphological data from soil survey to redefine boundary conditions of the flow system (e.g. Hoogmoed and Bouma, 1980; Bouma et al., 1982, 1983). These simulations assume that water only moves into vertical, continuous macropores at the soil surface when the infiltrative capacity of the adjacent soil surface is inadequate to accept the applied water at the given rate during a given time period. So, in fact, infiltration into the soil matrix next to the macropores is described with standard flow theory while continuous macropores create the opportunity for bypass flow where free water can reach relatively great depth in a short time. To calculate infiltration into soil surfaces with macropores, exact measurements of hydraulic conductivities are needed at pressure heads close to saturation. The crust test is particularly suitable for such measurements (Bouma, 1982). Bouma and Dekker (1978), using blue dyes, demonstrated bypass flow in the field in a dry clay soil with vertical shrinkage cracks and many more field experiments have been reported in literature showing identical phenomena (e.g. review by Van Schaik, 2009). Another example shows that simulation of downward transport of a conservative tracer through a water repellent sandy field soil is significantly underestimated when using a traditional piston-based model approach (Ritsema et al., 2005). Only through adequate description of the dynamic formation and disappearance of preferential flow paths, reasonable model results could be achieved (Ritsema et al., 2005, Kramers et al., 2005). Clue is that hysteresis in the water retention characteristics should be accounted for in describing and modeling flow and transport (Ritsema et al., 1998a; Ritsema and
Dekker, 2000). The formation, disappearance and reoccurrence of preferential flow paths during weather sequences with dry and wet periods have been monitored in detail in the field using advanced automated TDR devices (Ritsema et al., 1998b). Results indicate that preferential flow paths are quickly formed during single rain events, and disappear soon after rainfall ceases. During successive rain events, preferential flow paths reoccur at the same places, indicating that the position of these flow paths are fixed in space, and, among other factors, are determined by the wetting history (Ritsema et al., 1998b). This, in turn, might lead to the generation of soil heterogeneity in the long-term (Ritsema and Dekker, 1996). Recently, dynamic animations of infiltrating water through water repellent field soils have been constructed on basis of extensive field data (Oostindie et al., 2011) and by using software specifically designed for this purpose (Wesseling et al., 2008). These animations clearly show that water infiltration in homogeneous sandy soils prone to hydrophobic behaviour is far from uniform, and much more complex than earlier thought.

\section{Examples of using the hydropedological approach for simulating water movement in catchments}

\subsection{Introduction}

Many papers have been published on soil water regimes in catchment soils, using soil information, and a complete review is clearly beyond the scope of this text which deals with catchment classification. Three recent examples will, however, be briefly discussed to illustrate the use of soil 


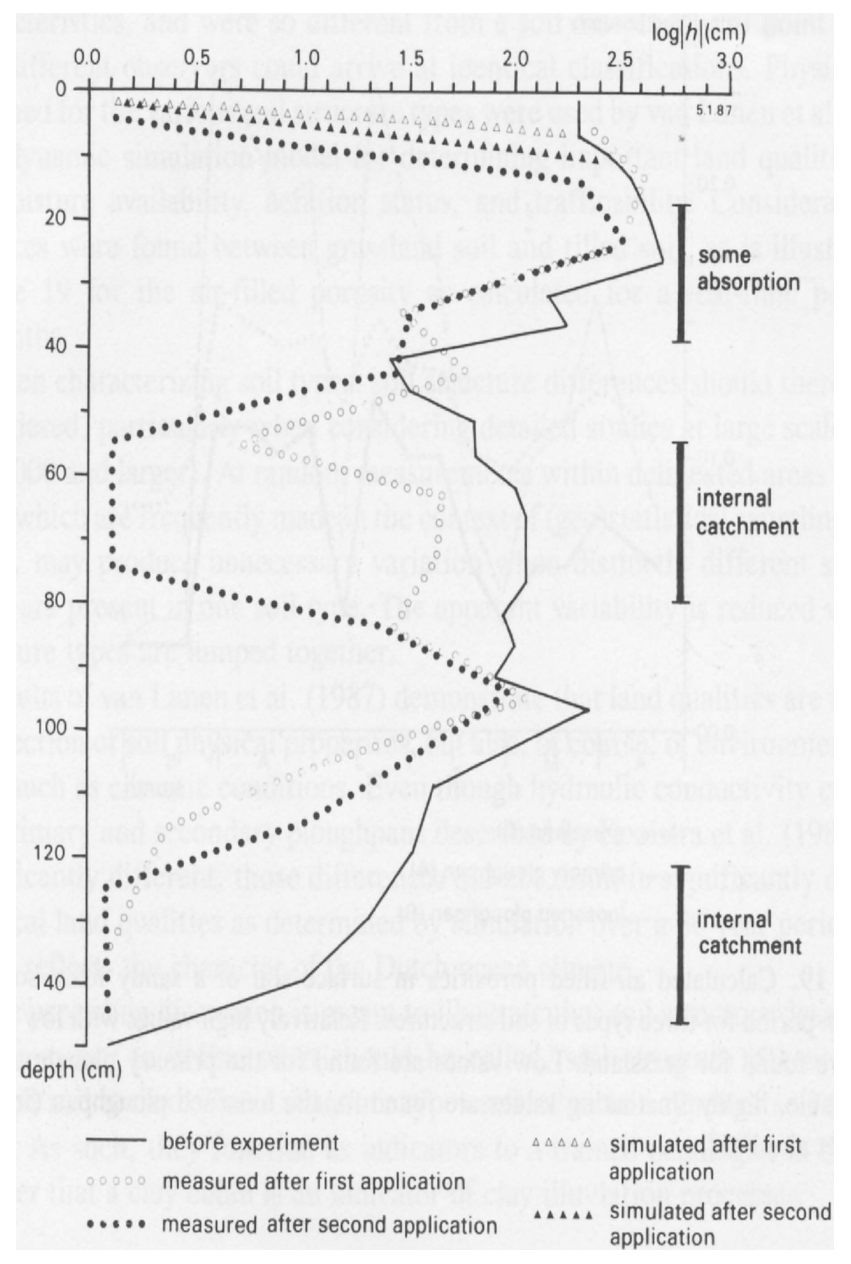

Fig. 3. Field- measured bypass flow and internal catchment in a silt loam soil with vertical macropores, demonstrating rapid wetting at around $60 \mathrm{~cm}$ and $140 \mathrm{~cm}$ depth (from van Stiphout et al., 1987).

information when simulating water regimes of catchments at different spatial scales.

The first study (Hunink et al., 2009) describes water regimes in the Upper Tana Basin in Kenya, an area of $17420 \mathrm{~km}$ square. The second one (van Schaik, 2009) discusses the effect of bypass flow on infiltration patterns in a catchment of $1 \mathrm{~km}$ square, as a recent example of a hydropedological field study. The third example (Immerzeel et al., 2009) illustrates that hydropedological processes, assessed with modern remote sensing techniques, can provide important validation data for models simulating water regimes in catchments.

\subsection{The Upper Tana basin study, Kenya}

Hunink et al. (2009) characterized water regimes in a large watershed with the specific objective to develop a procedure that supports so-called Green Water Credits - an investment facility for upstream farmers to improve their soil and water management which is targeted at increasing rainwater infiltration and storage in the soil and reducing evaporation from the soil. This will feed the underlying aquifer and combat surface runoff and erosion. Both effects are beneficial for downstream water users. The Green Water Credits investment facility is backed up by public and private partners. The latter are in particular the downstream water users as they benefit from upstream catchment management by rainfed agriculturalists. The project is part of a general tendency in policy circles, also in the European Union, to support farmers financially for so-called ecosystem services that used to be a side effect only of their commercial operations in dairy or arable farms. Payment of ecosystem services provides an extra inducement for farmers to improve their soil management and requires proper hydropedological information and distributed analysis tools.

The use of Hydrological Response Units (HRUs) was found particularly useful for this type of study, as they allow splitting up the model domain in unique combinations of topography, soil and land use, preserving the spatial distribution of soils. The area contained 2226 HRU's. However, procedures used are empirical, based on expert judgement and no indication is provided on internal variability of HRU's. The distributed hydrological model SWAT (Neitsch et al., 2002) was used to quantify water fluxes in the HRU's. The study made use of large datasets based on public domain (Upper Tana SOTER, AfricCover, FEWS-NET) as well as locally sourced climate, soil and land use data sets. A complete description of these datasets can be found elsewhere (Hunink et al., 2009). Missing entries of the soil parameterization are obtained by pedotransfer functions (van Engelen et al., 2005). Soil classification follows the Revised Legend of the Soil Map of the World (FAO, 2006). The area contained 68 soil types. The Upper Tana SOTER database includes the total available water capacity of the soil (simply expressed as water held between "field capacity" and "wilting point") and rootable depth. An important missing factor is the saturated hydraulic conductivity (Ksat) that should preferably be measured because it is highly variable and very small continuous soil pores can conduct large quantities of water (e.g. Bouma, 1992). But many measurements that would be needed for very large areas are not possible and pedotransferfunctions have been proposed, based on a statistical analysis of 350 measured Ksat values of various soils (Jabro, 1992). The dataset used here certainly contains questionable data obtained from small cores using the constant-head method that does not consider sample volume (Dane and Topp, 2002). The WOCAT land management database (WOCAT, 2007) was used to define appropriate management procedures to avoid soil degradation and erosion and to enhance infiltration and crop transpiration. Procedures were specifically defined for African conditions.

Many hydrological modeling studies consider soils only in the context of obtaining discharge curves for catchments which is attractive because measured discharges are often 


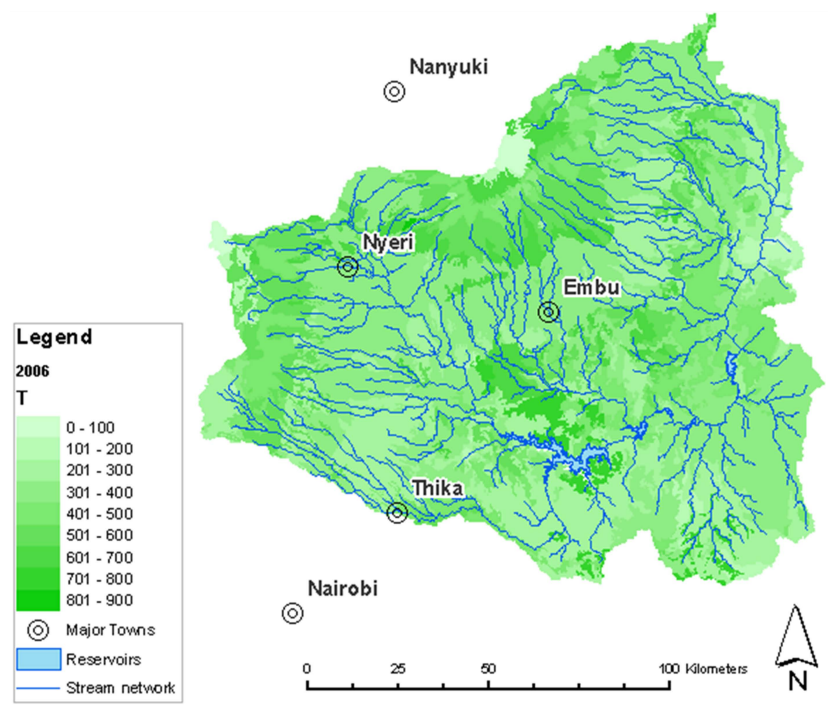

Fig. 4. Actual transpiration in Upper Tana, Kenya (mm per year).

available allowing calibration and validation of any model focused on calculating discharges. However, because of societal questions raised in the Green Water Credits program, the role of soils in this study had to be much broader in terms of being the main driver for soil evaporation, crop evapotranspiration, recharge to groundwater and erosion, all of which have different values at different locations in the catchment and all represent important properties of the catchment. Still, because of lack of alternatives, this SWAT modeling exercise was traditionally calibrated and validated with measured discharges at two locations (Hunink et al., 2009). Additional validation with remote sensing data, allowing, for example, an assessment of calculated evapotranspiration rates in the catchment, would have been attractive and is being investigated (e.g., Immerzeel and Droogers, 2008; Droogers and Kite, 2002).

A typical result of this study is shown in Fig. 4, indicating the calculated total transpiration by plants, which is equivalent to the amount of "green water". Transpiration is a function of various integrated processes based on soils, land cover and land management. An important sustainability characteristic is the amount of water that is actually recharging the groundwater. Calculations show that this calculated recharge is spatially quite variable (Fig. 5).

The ultimate objective of this study was to explore alternatives in management to increase the quantity of green water and water recharge. Explorative results of one particular adaptation strategy, implementation of contour strips, are shown in Fig. 6. It was assumed that these contour strips were implemented on all agricultural lands and the study explored what the impact would be in changes in groundwater recharge. The resulting map (Fig. 6) is now being used in Kenya for planning implementation of these contour strips but only in areas where this measure is expected to be most

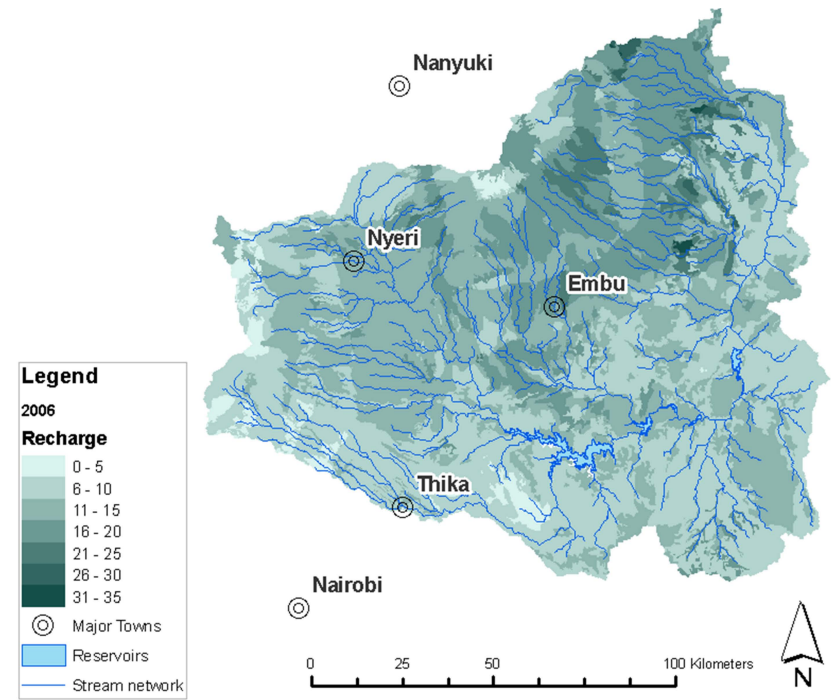

Fig. 5. Groundwater recharge in Upper Tana, Kenya (mm per year).

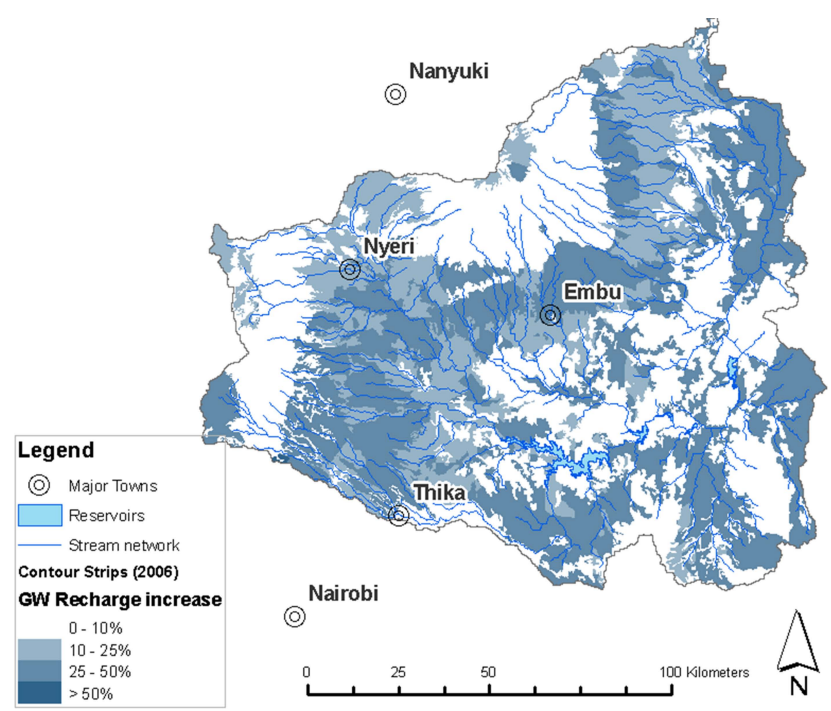

Fig. 6. Spatial distribution of relative increase in groundwater recharge for the contour strips scenario in Upper Tana, Kenya.

effective, considering the patterns of Fig. 6. This will result in a substantial reduction in costs as compared with constructing contour strips in the entire area and may serve as a nice illustration of the hydropedology approach at work.

This study demonstrates the use of soil maps and associated information for the modeling exercise. Of particular interest is the demand-driven character of the exercise focusing on an innovative application, the Green Water Credit facility, which has drawn major interest in the policy arena (see:www.greenwatercredits.org).

When faced with questions like this, the researcher is confronted with a dilemma. From a scientific point of view questions should, for example, be raised about the properties 
of the HRU's, used in the SWAT simulations. Just extrapolating point data for "representative" profiles to large areas of land represents a gross simplification ignoring variabilities involved. Still, a refusal to run a program such as this on scientific grounds would lead to a political free-for-all in practice, not guided by any information. This would be hard to justify but it is important to point out that this work represents a first effort which is essentially based on expert knowledge and that efforts to better express variability, errors and limitations involved are crucial and in progress. Any suggestion at this point in time that a proven standard procedure is being followed would be misleading at best.

\subsection{Spatial variability of infiltration}

Van Schaik (2009) studied spatial variability of infiltration patterns in a small watershed in the Dehasa study area (near Extramadura) in a semi-arid Spanish environment. Her study is one of the first to upscale phenomena of bypass flow (called preferential flow by the author) from the individual soil to a larger land area. A standardized shower was applied at 18 locations using water with a blue dye. Soils were excavated to observe patterns of infiltration indicating that bypass flow was prominent, particularly at the hilltops, while it was lower at the slopes and in the valley. Bypass flow was characterized by the depth of the uniform wetting front, the totally stained area, the maximum depth of the stains and the fraction of preferential flow as related to total flow. Regression analysis showed that four site-specific variables (vegetation, soil texture, slope and location in the landscape) could explain $50-66 \%$ of bypass values obtained. This is still a relatively low score indicating the need for further field studies. Still, different subareas could be distinguished in the catchment, each with characteristically different infiltration properties. Multiple measurements allowed an estimate of internal variability within each of the subareas. The study demonstrates the relevance of bypass flow when simulating water regimes in catchments. Moreover, when using the simple: "tipping bucket" flow model based on the static "field capacity" and "wilting point" concepts, bypass flow, as measured here, can be handled well by assuming that bypass water moves right into the subsoil beyond the rootzone. So far, also in the Hunink et al. (2009) study, the implicit assumption is made that soils are homogeneous and isotropic, which they are not. Much work is still needed to move beyond the concepts of homogeneity and isotropy and hydropedological expertise can be helpful here.

\subsection{Applying the Hydropedology approach to enhance model performance}

It is common practice in hydrology to calibrate a hydrological model using a few discharge gauges near the outlet of a catchment. Model parameters are adapted until a satisfactory relation between observed and modelled discharge is obtained. Although calibration results may seem statistically significant at a high degree of confidence this is not a guarantee that the entire model is a correct representation of real conditions in the catchment. Process-based distributed hydrological models usually combine high spatial heterogeneity with a large number of model parameters and this may result in the equifinality problem, e.g. multiple parameter combinations yield the same result. The main problem is, however, that a good comparison between observed and simulated discharge does not ensure that other processes, such as evapotranspiration, crop growth, groundwater recharge are correctly represented. The right result may be obtained for the wrong reason. A promising potential solution for these problems in model calibration is the use of spatially distributed actual evapotranspiration (ETact) as a readily available data source. Immerzeel et al. (2009) tested this approach for the Guadalquivir basin in southern Spain of $57000 \mathrm{~km}^{2}$ (Fig. 7) using a time series of MODIS- based ETact maps based on the SEBAL algorithm (Bastiaanssen et al., 2005) and the Soil and Water Assessment Tool (SWAT; Neitsch, 2002). Figure 8 shows the spatial patterns of actual evapotranspiration at HRU level for observed values using Remote Sensing (SEBAL) and the model (SWAT). The spatial patterns are depicted very well by SWAT. The Guadalquivir valley, where most irrigated agriculture is found, is clearly shown and no large spatial biases can be identified. The scatterplot in Fig. 9 shows good agreement between measured and calculated ET's as expressed by r-square of 0.94 . A limited number of deviating values are shown, indicating that observations and model do not always match. However, these values are associated with special conditions which can be explained. Values in ellipse A are in the model classified as open water but occur in reality in dried areas following low rainfall conditions. Values in ellipse B are located in the rice paddy area and have an extremely high ETact. For these areas the soil available water capacity as specified in the model is probably too low to achieve a similar ETact as observed. Ellipse $\mathrm{C}$ contains only two values that are most likely misclassified as irrigated agriculture, while in ellipse D irrigated agriculture was erroneously classified as rangeland. For the values in ellipse $\mathrm{E}$ the deviations are probably due to an underestimation of plant stress factors (nutrients, soil, pests and diseases).

This example illustrates that modern remote sensing techniques, can provide important validation data for models simulating water regimes in catchments when these models also consider development of vegetation or crops, which is necessary when characterizing catchments in the growing season. Recently, new proximal soil sensing techniques also provide data that is highly valuable to calibrate and validate simulation models (Viscarra Rossel et al., 2010). But also here, the error involved in translating the received signals into values for evapotranspiration and soil properties needs to be considered and presented as part of results obtained. 


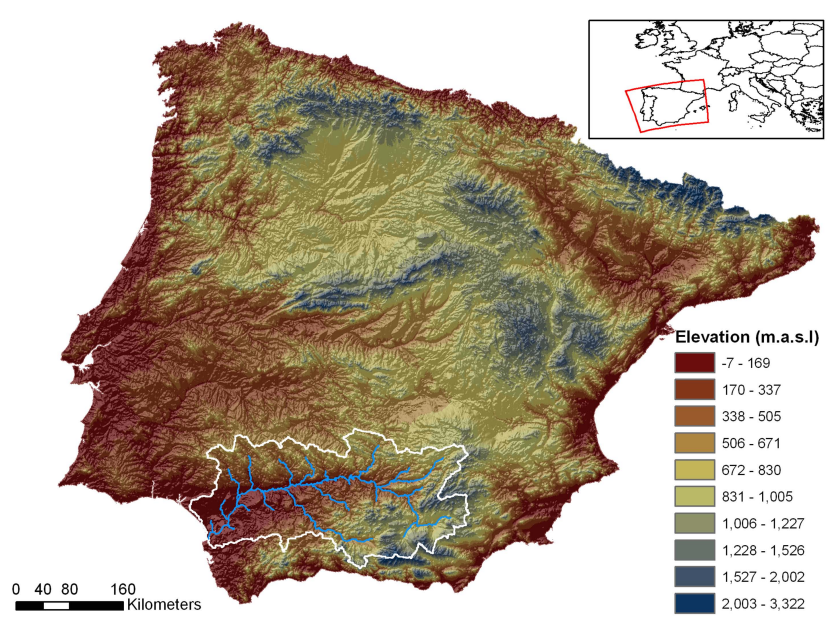

Fig. 7. Study area Guadalquivir in Southern Spain.

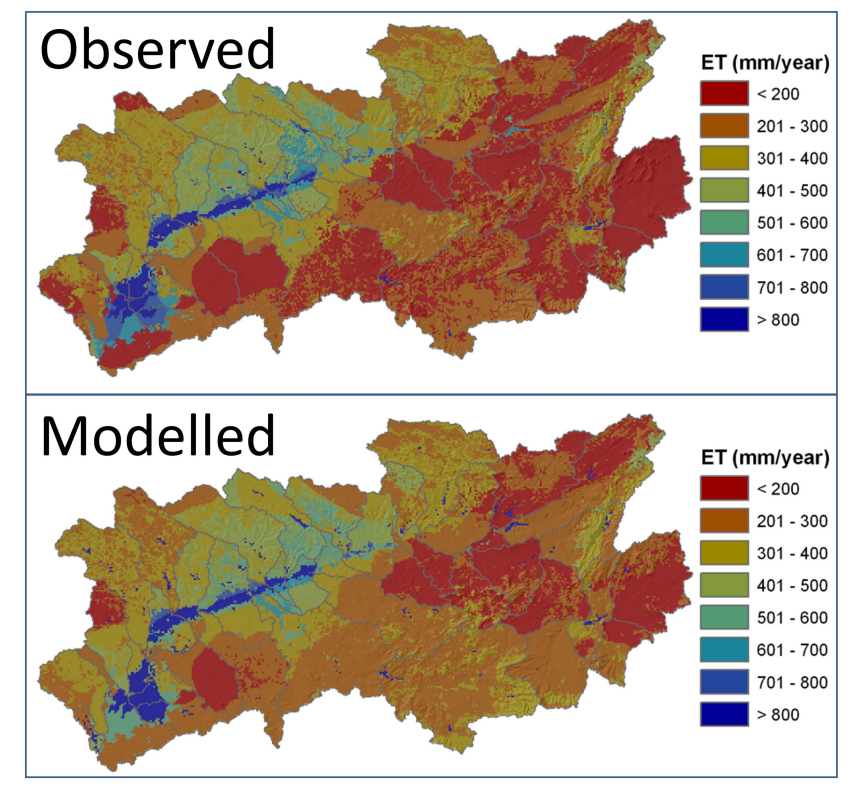

Fig. 8. Observed (top) and modelled (bottom) actual evapotranspiration from October 2004 to September 2005 at HRU level.

\section{Implications for catchment classification}

First, the question should be answered which function, if any, catchment classification can and should play in the overall research programs on catchment hydrology. This is, of course, for the profession to decide but the five functions, discussed above for soil science, would probably also be relevant for catchment hydrology. But following the experiences provided by developing soil classification, this would require the definition of permanent characteristics of the catchment to be used as differentiating characteristics for the different categories of any classification scheme. One could think of, for example, geology, soils, topography, relief, degree of branch-

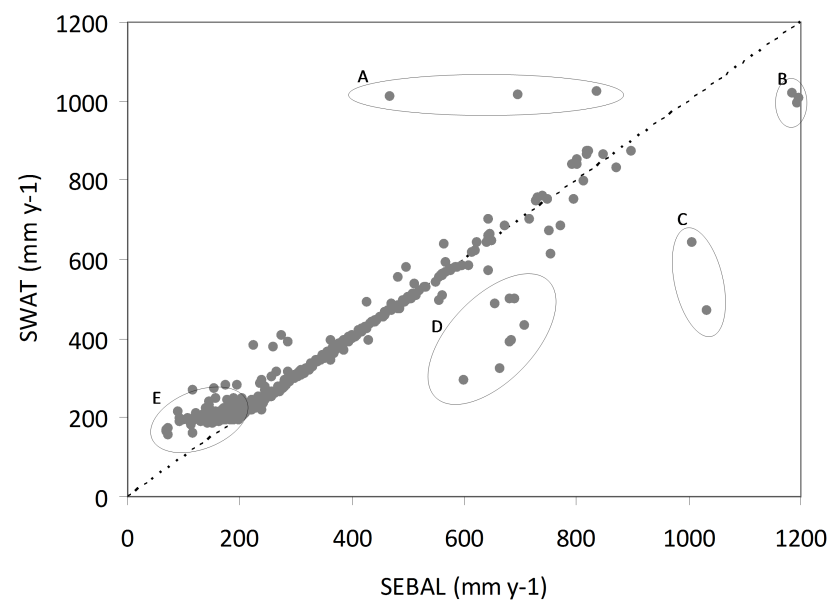

Fig. 9. Comparison observed (SEBAL) and modelled (SWAT) calibration results. Ellipses $\mathbf{A}$ to $\mathbf{E}$ show areas where model differs from observations.

ing of surface flow channels and climate. Considering soils, names of classification units may appear mysterious for non soil scientists. However, certain permanent soil characteristics, such as texture, thickness of surface horizons or depth to slowly permeable subsurface horizons, and - less permanentthe organic matter content can be shown for a given region as single value maps that can rapidly be generated by Geographical Information Systems when appropriate soil maps and databases are available (see case-study Tana Basin, Kenya, presented above). This direct type of soil information can be helpful when developing classification schemes for catchments.

Soil Taxonomy (Soil Survey Staff, 1999) distinguishes Soil Orders, Suborders, Groups, Subgroups, Families and Series, each one with differentiating characteristics of decreasing significance for each lower classification category. Reaching agreement on a final soil classification scheme has taken at least forty years of intense discussions in the period 1960-2000 and an investment of an immense amount of energy by the pedology community. The question may be raised whether this time was well spent or if more emphasis on functional soil characterization would have been more profitable for the profession? Catchment hydrologists would be well advised to reflect on this question as embarking on a serious classification effort will involve a substantial effort.

Currently, tentative classification schemes of catchments, as reported in this special HESS issue, usually focus on discharge characteristics as a basis for differentiation. Others have argued for a combination of metrics such as a catchment's "form" (including geomorphologic and pedologic characteristics) as well as dynamic catchment response characteristics. Regardless of the metrics chosen, there is currently no well-defined set of criteria to classify catchments (Wagener et al., 2007). Of course, discharge characteristics are important features of watersheds but perhaps 
more in terms of a dynamic property as a function of different boundary conditions than as a differentiating characteristic for catchment classification. Comparable discharges may result from different weather conditions or different processes in various catchments. Also, and more importantly, a classification based on current discharges will not be valuable when trying to predict catchment behaviour under changed conditions of climate or land-use change, which represent the real problems of the future.

In view of the difficulties still encountered when simulating water regimes in catchments and considering the major investment needed to develop a widely accepted classification scheme, it would perhaps be wiser at this point in time to focus energy on first trying to improve simulation results of watershed hydrology before developing catchment classification schemes. As discussed, incorporating hydropedological data to improve the characterization of the unsaturated zone may help. Also, it would be advisable to broaden the traditional focus on catchment discharge as a differentiating characteristic by paying more attention to other features that arise from societal concerns. The Green Water Credits example of Kenya, presented above, illustrates, for example, an innovative approach presenting a new differentiating catchment characteristic ("Green Water") based on a practical question.

In pedology, soil classification has received major emphasis for several decades. Lately, functional characterization of soil units in space and time is slowly receiving more attention (e.g. Bouma, 1989; Stolte et al., 1996, 2003; Hessel et al., 2003) and this is particularly interesting for practical applications. But as soil scientists were inward looking while developing complicated classification schemes, soil data were not used by hydrologists and engineers as they could have been. Perhaps, there are lessons here for hydrologists studying watershed hydrology. Why not focus first on improving the functional characterization of catchments in the context of societal issues raised and focus later on catchment classification when more data and insight have been generated?

Acknowledgements. Comments and recommendations from reviewers have improved the quality of this paper and is highly appreciated.

Edited by: T. Wagener

\section{References}

Bastiaanssen, W. G. M., Noordman, E. J. M., Pelgrum, H., Davids, G., and Allen, R. G.: SEBAL for spatially distributed ET under actual management and growing conditions, J. Irrig. Drain. EASCE, 131, 85-93, 2005.

Beven, K.: Searching for the Holy Grail of scientific hydrology: $Q t=(S, R, \Delta t) \mathrm{A}$ as closure, Hydrol. Earth Syst. Sci., 10, 609618, doi:10.5194/hess-10-609-2006, 2006.

Booltink, H. W. G. and Bouma, J.: Bypass flow. In: Methods of Soil Analysis. Part 4: Physical methods, SSSA Book series: 5. Madison, Wis., 930-933, 2002.
Bouma, J.: Soil morphology and preferential flow along macropores, Agric. Water Manage., 3(4), 235-250, 1981.

Bouma, J.: Measuring the hydraulic conductivity of soil horizons with continuous macropores, Soil Sci. Soc. Am. J., 46(2), 438441, 1982.

Bouma, J.: Using soil survey data for quantitative land evaluation, edited by: Stewart, B. A., Adv. Soil Sci., 9, Springer Verlag, New York: 177-213, 1989.

Bouma, J.: Influence of soil macroporosity on environmental quality, Adv. Agron., 46, 1-37, 1991.

Bouma, J.: Effect of soil structure, tillage and aggregation upon soil hydraulic properties. Advances in Soil Science. Interacting Processes in Soil Science, edited by: Wagenet, R. S., Baveye, P., and Stewart, B. A., Lewis Publishers, Boca Raton-Ann ArborLondon-Tokyo, 1-37, 1992.

Bouma, J.: Hydropedology as a powerfool tool for environmental policy research, Geoderma, 131, 275-287, 2006.

Bouma, J. and Dekker, L. W.: A case study on infiltration into dry clay soil. I Morphological observations, Geoderma, 20, 27-40, 1978.

Bouma, J., Belmans, C. F. M., and Dekker, L. W.: Water infiltration and redistribution in a silt loam subsoil with vertical worm channels, Soil Sci. Soc. Amer. J., 46(5), 917-921, 1982.

Bouma, J., Belmans, C. F. M., Dekker, L. W., and Jeurissen, W. J. M.: Assessing the suitability of soils with macropores for subsurface liquid waste disposal, J. Environm. Qual., 12, 305-311, 1983.

Bouma, J., Stoorvogel, J. J., and Sonneveld, M. P. W: Land Evaluation for Landscape Units. Chapter E6 in Handbook of Soil Science, edited by: Summer, M. E., CRC Press. Boca Raton, USA, in press, 2011.

Dane, J. H. and Topp, G. C.: Methods of Soil Analysis. Part 4. Physical Methods, No.5 in the Soil Science Society of America Book Series, SSSA, Madison, Wis. USA, 2002.

Droogers, P. and Bouma, J.: Soil survey input in exploratory modelling of sustainable soil management practices, Soil Sci. Soc. Amer. J., 61, 1704-1710, 1997.

Droogers, P. and Kite, G. W.: Remotely sensed data used for modeling at different hydrological scales, Hydrol. Process., 16, 15431556, 2002.

FAO: World Reference Base for Soil Resources 2006, 2nd Edn., World Soil Resources Reports, No. 103, Rome, 2006.

Gerasimov, J. P.: A modern Dokuchayev approach to soil classification and its uses on the soil maps of the U.S.S.R. and of the world, Soviet Soil Sci., 6, 563-571, 1964.

Hessel, R., Messing, I., Liding, C., Ritsema, C. J., and Stolte, J.: Soil erosion simulations of land use scenarios for a small Loess Plateau catchment, Catena, 54, 289-302, 2003.

Hoogmoed, W. B. and Bouma, J.: A simulation model for predicting infiltration into cracked clay soil, Soil Sci. Soc. Amer. J., 44(3), 458-461, 1980.

Hunink, J. E., Immerzeel, W. W., and Droogers, P.: Green Water Credits for the Upper Tana Basin, Kenya. Phase II-Pilot Operations. Biophysical assessment using SWAT, Report FutureWater 84, Wageningen, The Netherlands, 2009.

Immerzeel, W. W. and Droogers, P.: Calibration of a distributed hydrological model based on satellite evapotranspiration, J. Hydrol., 349, 411-424, 2008.

Immerzeel, W. W., Rutten, M. M., Droogers, P., de Jong, S. M., and 
Bierkens, M. F. P.: Spatial downscaling of TRMM precipitation using vegetative response on the Iberian Peninsula, Remote Sens. Environ., 113, 362-370, 2009.

Jabro, J. D.: Estimation of saturated hydraulic conductivity of soils from particle size distribution and bulk density data, Journal of the American Society of Agricultural Engineers, 35(2), 557-560, 1992.

Kramers, G., van Dam, J. C., Ritsema, C. J., Stagnitto, F., Oostindie, K., and Dekker, L. W.: A new modeling approach to simulate preferential flow and transport in water repellent porous media: model sensitivity, and effects on crop growth and solute leaching., Austr. J. Soil Res., 43, 371-382, 2005.

Kuilenburg, J. van, de Gruijter, J. J., Marsman, B. A., and Bouma, J.: Accuracy of spatial interpolation between point data on soil moisture supply capacity, compared with estimates from mapping units, Geoderma, 27(4), 311-325, 1982.

Lagacherie, P.: Digital Soil Mapping: A State of the Art, in: Digital Soil Mapping with Limited Data, edited by: Hartemink, A. E., McBratney, A., and Mendonca-Santos, M. L., Springer Verlag, 2008.

Lin, H., Bouma, J., Pachepsky, Y., Western, A., Thompson, J., van Genuchten, R., Vogel, H. J., and Lilly, A: Hydropedology: Synergistic integration of pedology and hydrology, Water Resour. Res., 42, W05301, doi:10.1029/2005WR004085, 2006.

Neitsch S. L., Arnold, J. G., Kiniry, J. R., Williams, J. R., and King, K. W.: Soil and Water Assessment Tool (SWAT). Theoretical Documemtation, version 2000, Taxes Water Resources Institute, College Station, Texas, 2002.

Oostindie, K., Dekker, L. W., Wesseling, J. G., and Ritsema, C. J.: Water movement in an undulating sandy soil prone to water repellency, Vadose Zone J., 10, 262-269, doi:10.2136/vzj2010.0051, 2011.

Pachepsky, Y. A. and Rawls, W. J. (Eds): Development of pedotransfer functions in soil hydrology, Elsevier, Developments in Soil Science, 30, Amsterdam, the Netherlands, 2004.

Pulleman, M. M., Bouma, J., van Essen, E. A., and Meijles, E. W.: Soil organic matter content as a function of different land use history, Soil Sci. Soc. Amer. J., 64, 689-694, 2000.

Ritsema, C. J. and Dekker, L.W.: Water repellency and its role in forming preferred flow paths in soils, Austr. J. Soil Res., 34, 475487, 1996

Ritsema, C. J. and Dekker, L. W.: Preferential flow in water repellent sandy soils: Principles and modeling implications, J. Hydrol., 231-232, 308-319, 2000.

Ritsema, C. J., Dekker, L. W., Hendrickx, J. M. H., and Hamminga, W.: Preferential flow mechanism in a water repellent sandy soil, Water Resour. Res., 29, 2183-2193, 1993.

Ritsema, C. J., Dekker, L. W., Nieber, J. L., and Steenhuis, T. S.: Modeling and field evidence of finger formation and finger recurrence in a water repellent sandy soil, Water Resour. Res., 34, 555-567, 1998a.
Ritsema, C. J., Nieber, J. L., Dekker, L. W., and Steenhuis, T. S.: Stable or unstable wetting fronts in water repellent soils - effect of antecedent moisture condition, Soil Till. Res., 47, 111-123, 1998b.

Ritsema, C. J., Dam, J. C. van, Dekker, L. W., and Oostindie, K.: A new modelling approach to simulate preferential flow and transport in water repellent porous media: model structure and validation, Aust. J. Soil Res., 43, 361-369, 2005.

Smith, G. D.: Lectures on soil classification, Pedologie Special No. 4, 1-135, 1965.

Soil Survey Staff: Soil Taxonomy: a basic system of soil classification for making and interpreting soil surveys (2nd Edn.), Washington, DC, US Department of Agriculture Soil Conservation Service, 1999.

Sonneveld, M. P. W., Bouma, J., and Veldkamp, A.: Refining soil survey information for a Dutch soil series using land use history, Soil Use Manage., 18, 157-163, 2002.

Sonneveld, M. P. W., Hack-ten Broeke, M. J. D., van Diepen, C. A., and Boogaard, H. L.: Thirty years of systematic land evaluation in the Netherlands, Geoderma, 156, 84-92, 2010.

Stolte, J., Ritsema, C. J., Veerman, G. J., and Hamminga, W.: Establishing temporal and spatially variable soil hydraulic data for use in a runoff simulation in a loess region of the Netherlands, Hydrol. Process., 10, 1027-1034, 1996.

Stolte, J., van Venrooij, B., Zhang, G., Trouwborst, K. O., Liu, G., Ritsema, C. J., and Hessel, R.: Land-use induced spatial heterogeneity of soil hydraulic properties on the Loess Plateau in China, Catena, 54, 59-76, 2003.

Van Engelen, V. W. P, Batjes, N. H, Dijkshoorn, K., and Huting, J.: Harmonized Global Soil Resources Database (Final Report), Report 2005/06, ISRIC - World Soil Information, Wageningen, available at: www.isric.org, 2005.

Van Schaik, N. L. M. B.: Spatial variability of infiltration patterns related to site characteristics in a semi-arid watershed, Catena, 78, 36-47, 2009.

van Stiphout, T. P. J., van Lanen, H. A. J., Boersma, O. H., and Bouma, J.: The effect of bypass flow and internal catchment of rain on the water regime in a clay loam grassland soil, J. Hydrol. 95(1/2), 1-11, 1987.

Viscarra Rossel, R. A., Mc Bratney, A., and Minasny, B.: Proximal Soil Sensing, Springer Verlag, 2010.

Wagener, T, Sivapalan, M., Troch, P., and Woods, R.: Catchment classification and hydrologic similarity, Geography Compass, 1(4), 901-931, 2007.

Wesseling, J. G., Oostindie, K., Dekker, L. W., Van den Elsen, H. G. M., and Ritsema, C. J.: Animating measured precipitation and soil moisture data, Computers and Geosciences, 34, 658-666, 2008.

WOCAT: Where the land is greener. Case studies and analysis of soil and water conservation initiatives worldwide, edited by: Liniger, H. and Critchley, W., 2007. 